\title{
Effect Surface Roughness on Fatigue Crack Propagation Behaviour of Fibre Metal Laminates (FMLs)
}

\author{
A. Purnowidodo*, S. Sofyan Arief and F. Hilmi Iman \\ Mechanical Engineering Department, University of Brawijaya, Jl. MT. Haryono 167, \\ Malang 65145, Jawa Timur, Indonesia \\ *Email: anindito@ub.ac.id \\ Phone: +62 341 552491; Fax: +62 341552491
}

\begin{abstract}
In the present study, the effect of surface roughness of the metal lamina at the interface of fibre metal laminates (FMLs) on the crack propagation behaviours was investigated for different fibre orientation. The FMLs was made by combining the aluminium and the carbon fibre-epoxy composite lamina. The increasing of the aluminium surface roughness at the interface causes the tensile strength to increase for every fibre orientation. The highest tensile strength is 282 and $367 \mathrm{MPa}$., respectively for fibre orientation $0^{\circ} / 90^{\circ}$ and $-45^{\circ} / 45^{\circ}$ when the surface roughness is $2.89 \mu \mathrm{m}$. The increasing surface roughness causes the development of the delamination taking place at the interface is more difficult, and it leads to the shear strength at the interface to increase. Because of this, the tensile strength increases. However, the lifetime is not only influenced by the interface shear strength but also the stress concentration just in front of the crack tip as well as the surface roughness itself leading to the crack to be initiated from the rougher surface. The longest fatigue life is 180000 cycles in the case of the fibre orientation $0^{\circ} / 90^{\circ}$ with the surface roughness of $1.78 \mu \mathrm{m}$, and in the case of fibre orientation of $-45^{\circ} \%+45^{\circ}$ the longest fatigue life is 420000 cycles when the surface roughness is $0.33 \mu \mathrm{m}$. The results of the study show that the surface roughness affects the tensile strength and crack propagation behaviour.
\end{abstract}

Keywords: Surface roughness; crack propagation, lifetime, delamination, shear strength; stress concentration.

\section{INTRODUCTION}

Nowadays the use of composites cannot be avoided in many aspects of daily life such as transportations, sports and music. Even, the usage of the composite is in common in military industries. Those aspects involve many kinds of composites. One of them is a laminate composite type used as parts of structures. This type of composite consists of at least two different materials of laminates. In general, the laminate composite is made to obtain a material having a combination of high strength and lightweight. Hence, a lightweight metal such an aluminium and a fibre-epoxy reinforced composite laminate are combined to obtain the fibre metal laminates (FMLs) composite. In this case, the fibre may be glass and carbon fibre, which is remarkably high strength in comparison to the lightweight metal [1-3]. In service, components of structures are rare to be subjected to static loads. However, instead of the static loads, dynamic loads are most in common to be carried by components in various shapes [4-6]. It is well-known that a dynamic load is more dangerous than a static load although a dynamic load applied is much lower than the strength of a material. The dynamic load can initiate a crack locally in a component, 
and it may propagate to its critical length of a material of a component. If the crack propagating is undetected before reaching the critical length, it will endanger that component integrity. The crack propagation caused by dynamic loads may also occur on a component of a structure in which the material is FMLs [7-9]. The crack caused by that dynamic load is known as the fatigue crack $[4,5]$.

The fatigue crack initiation in the FMLs is similar to that occurring on a single laminate of metal [2, 7-9]. However, as the number of load cycles increase, the crack propagates to become a long crack. The crack is defined as long crack when the unaided eye can observe the crack. The long crack only takes place on the metal laminate whereas the fibre reinforced composite is still intact over the crack region [2, 7-14]. The crack propagation rate on the metal laminate of FMLs is lower than that occurs on a monolithic metal. This is caused by the fibre-bridging effect that occurs over the crack wake behind the crack tip. When the long crack takes place on the metal laminate, the stress carried by the metal laminate over the crack region is transferred to the fibre reinforced composite. This transferred stress is well known as bridging stress. Because this stress occurs over the crack wake behind the crack tip, it causes the shear stress to develop at the interface between the metal laminate and the fibre reinforced composite laminate. Due to the shear stress is cyclic loads, the delamination between the metal laminate and the fibre reinforced composite lamina can develop over the crack wake. The existence of the bridging stress reduces the opening of the crack tip. The reduction of the opening of the crack tip is an indication that the stress advances effectively the crack is low [2,6]. Therefore, it decreases effectively the crack propagation rate taking place at the metal laminate. However, if the delamination on the crack wake is easy to develop, the crack propagation rate is increased. The increasing of the crack propagation rate is caused by the decreasing of the bridging stress at the delamination region $[2,7]$.

In addition to the type of materials composing the FMLs, the strength of the FMLs is also strongly influenced by the inter laminates shear strength in adhesively bonded [10]. The shear strength depends on surface conditions of materials composing the FMLs. The surface roughness can increase the shear strength at the interface of the laminates due to the increasing mechanical-interlocking adhesion [15]. Because the development of delamination at interfaces of the FMLs caused by the cyclic shear stress over the crack region, the interlaminate shear strength has a key role to prevent, the delamination occurring. Therefore, in the present study, the effects of the surface roughness of metal laminate to the FMLs strength and the crack propagation behaviours are investigated. It is an important to know the crack propagation behaviour of the FMLs in associated with the surface roughness because an accurate assessment of a lifetime of a component based on the crack propagation is determined by the behaviour how the crack propagates, especially when the assessment is carried out by the linear elastic fracture mechanic method $[4,5]$.

\section{METHOD OF STUDY}

To make FMLs, the commercially pure aluminium with a thickness of $0.5 \mathrm{~mm}$ was selected for the metal laminate. After being heat treated in $300^{\circ} \mathrm{C}$ for an hour and cooled in the furnace, the yield and ultimate tensile strength of the aluminium were 60 and 70 $\mathrm{MPa}$., respectively, and the maximum elongation was $1.4 \%$. The fibre reinforced composite laminate was made by combining twill-woven carbon fibre and epoxy, and Figure 1 shows the example of the fibre. The strength of the fibre is $1.27 \mathrm{GPa}$., and the maximum elongation is $2.75 \%$. Figure 2 shows the shape and the dimension of the 
specimen, respectively, for tensile and fatigue test as well as the laminates arrangement of them at which those type of specimens have the same thickness. The length of $50 \mathrm{~mm}$ from both ends of the specimen was used for gripping on the testing machine. As the strength of FMLs is strongly influenced by the bonding at the interface of the metal and fibre/epoxy laminate [10], the shear-strength test at the interface was carried out. For this purpose, the specimen with shape and dimension was made as shown schematically in Figure 3. The shear-strength test at the interface only was carried out because the fatigue load causes cyclic shear-stress at the interface leading to the delamination, and the shear strength at the interface will determine the development of the delamination $[8,15]$.

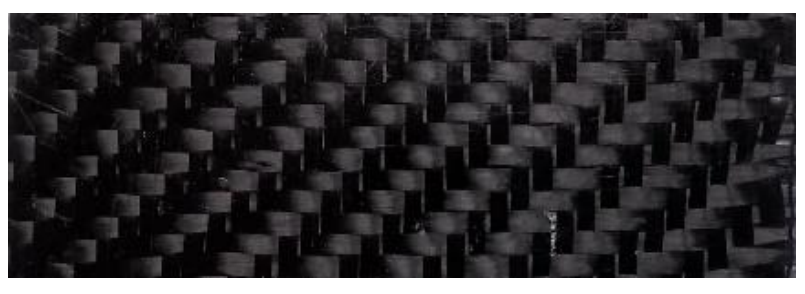

$2 \mathrm{~cm}$

Figure 1. An example of twill woven carbon fibre
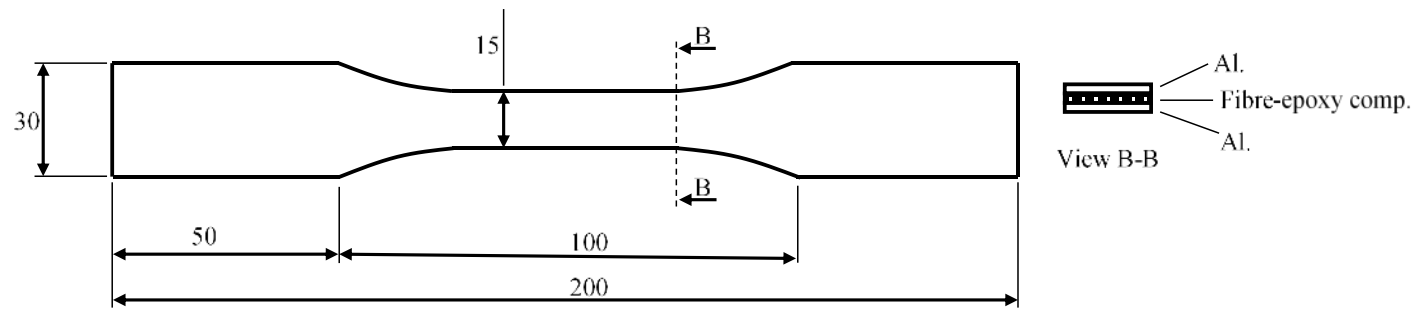

(a)

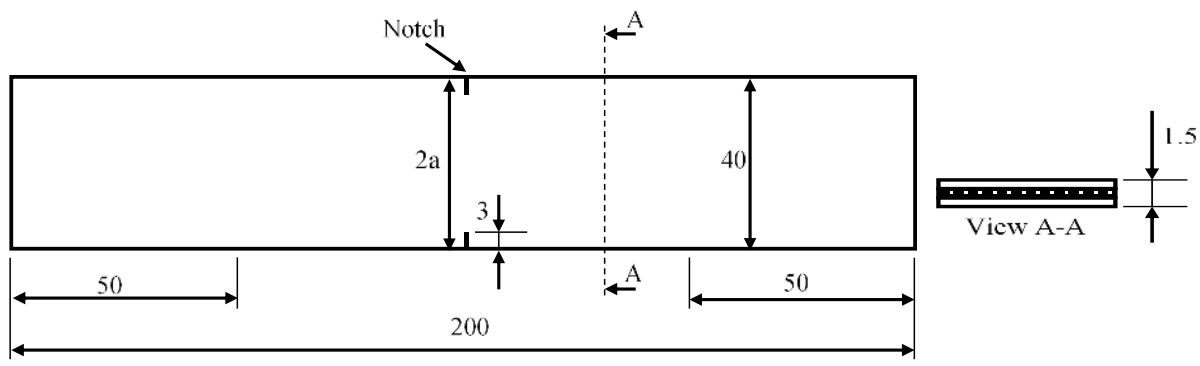

(b)

Figure 2. The shape and the dimension of (a) tensile and; (b) fatigue test specimen.

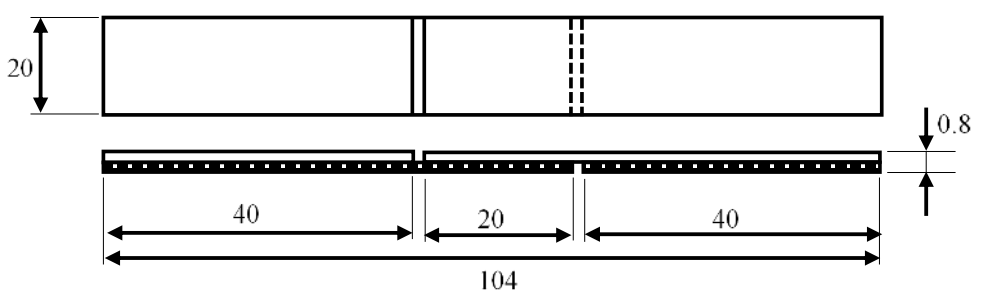

Figure 3. The shape and dimension for shear strength test. 
In the present work, a vacuum assisted resin transfer moulding (VARTM) technique in Figure 4 was carried out at the laboratory room temperature condition to produce specimens of FMLs composites. The resin-epoxy was used as adhesive to make the epoxy-fibre composite laminate, and the curing time of the epoxy as recommended by the manufacturer was 12 hours. The fibre orientation was arranged in this manner to be directed to $0^{\circ} / 90^{\circ}$ and $-45^{\circ} / 45^{\circ}$, respectively, to the load direction. The double-edge crack type of specimen for the fatigue test was selected; thus the sharp notch with $3.0 \mathrm{~mm}$ in length and $0.2 \mathrm{~mm}$ in width was cut carefully by a saw on every edge of the specimen. To make the specimens, the mixture of epoxy-hardener with ratio 2:1 was poured into the container, and then the vacuum pump sucked the epoxy from the container. Before that, depending on the kind of specimens, the sequence of the laminate was arranged as indicated in Figure 1 and Figure 2, respectively, and then it was put into the mould as that manner. Afterwards, it was wrapped by the plastic bag film, which was sealed to prevent air from being sucked into the mould and to keep the vacuum condition. After being filled up completely the epoxy into the mould, the vacuum pump was turned off, and then it was left for 12 hours for curing. By using this technique, the specimen thickness of 1.3 mm was obtained.

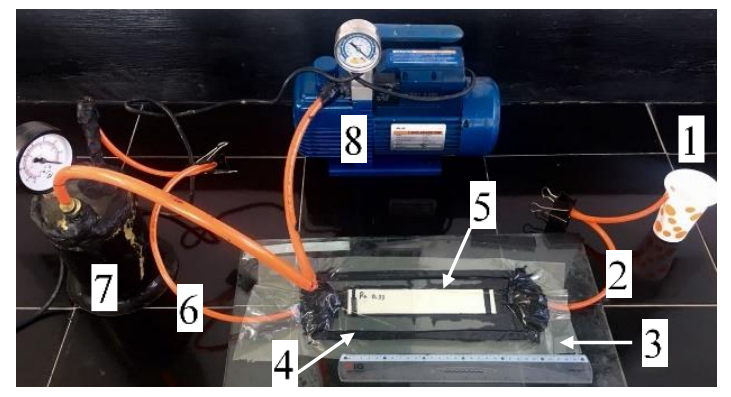

1. Epoxy container

2. Inlet tube

3. Bag film

4. Sealant tape

5. Specimen mould

6. Outlet tube

7. Epoxy trap

8. Vacuum pump

Figure 4. Vacuum assisted resin transfer molding (VARTM)

After being heat treated and before being shaped as specimens shown schematically in Figure 2 and Figure 3, the $20 \mathrm{~cm}$ x $20 \mathrm{~cm}$ of the monolithic aluminium sheet was sandblasted to vary the level of surface roughness. In this process, the size of the sand particle stated in the mesh number was 70 . The working distance from the nozzle to the aluminium surface was $1 \mathrm{~m}$, and it was carried out with a scan speed of $20 \mathrm{~mm} / \mathrm{s}$ and a pressure of 5.0 bar. The scanning was conducted once up to five times to obtain different surface roughness $\left(\mathrm{R}_{\mathrm{a}}\right)$, respectively, and the levels of $\mathrm{R}_{\mathrm{a}}$ obtained were 1.68 , $1.78,1.93,2.13$ and $2.89 \mu \mathrm{m}$ in average. The surface roughness test was carried with a surface roughness tester with measuring range $0.005 \sim 16 \mu \mathrm{m}$.

The servo-hydraulic fatigue machine with a maximum capacity of $50 \mathrm{kN}$. was used to carry out the fatigue crack propagation test. Besides the fatigue test, the machine has the capability to carry out the static test; thus, the tensile test of the FMLs was conducted in this machine. The displacement speed in the tensile test was $0.02 \mathrm{~mm} / \mathrm{s}$. The extensometer with $50 \mathrm{~mm}$ gauge length and $5 \mathrm{~mm}$ measuring range was used to measure the displacement. The shear strength was also carried out in the same conditions as the tensile test. In the fatigue test, the specimens were subjected to the constant amplitude stress with a frequency of $6 \mathrm{~Hz}$. and the stress ratio $(\mathrm{R})$ of 0 . The stress ratio is defined as the ratio of the minimum $\left(S_{\min }\right.$ ) to maximum constant amplitude stress $\left(S_{\max }\right)$. The maximum constant amplitude stress $\left(S_{\max }\right.$.) was determined to be $1 / 3$ of the tensile strength (TS) because in general, a component is designed to be capable of carrying load 
up to $1 / 3$ of its tensile strength when it is subjected to dynamic loads [4, 5]. Table 1 shows the conditions for fatigue testing. The $\mathrm{R}_{\mathrm{a}}$ of $0.33 \mu \mathrm{m}$ is the aluminium surface roughness without being sandblasted. In order the crack propagation was observable, the exterior surface of aluminium laminate of the FMLs was polished by an emery paper to obtain a mirror-like surface, and the observation was carried out by aid of a travelling digitally microscope with accuracy $10 \mu \mathrm{m}$. The crack length, $2 \mathrm{a}$, was measured including the notches at both sides of the specimen. In the present investigation, the three specimens were tested in the fatigue test in every test condition, and the result of the test was based on the average of them. Similarly, this also carried out on the tensile and shear test, respectively.

It has been already known that the delamination taking place on the laminate interface of FMLs affects the strength and the fatigue crack propagation [2, 7-9]. Because of those, to indicate whether the delamination takes place or not, the fracture specimens after being tested for the tensile strength and the fatigue crack propagation, respectively, were immersed into a die in black colour for 24 hours. If the delamination took place, the die would infiltrate to the surface of the laminate on which the delamination occurs, and the delaminated surface would be expected to be in black. To know the area of the delamination, the free software of Image $\mathrm{J}$ was used. Also, because the crack propagation is affected by the stress distribution just in front of the crack tip of the aluminium laminate, the stress distribution in association with the aluminium-surface roughness in front of the crack tip was investigated. The computer simulation, which based on the ANSYS software code standard was carried out for the investigation. In the simulation, the cracked FMLs is modelled and meshed as shown in Figure 5. However, the stress distribution when the semi-crack length, a, had been propagated to be $10 \mathrm{~mm}$ in length is presented in the study because it was considered to be long enough. Thus, the notch effect can be ignored [16]. Also, it can represent an indication of how the stress distributed just in front of the crack tip.

Table 1. Fatigue testing conditions

\begin{tabular}{cccc}
\hline No. & $\mathrm{R}_{\mathrm{a}}(\mu \mathrm{m})$ & $\mathrm{S}_{\max }(\mathrm{MPa})$. & $\mathrm{R}$ \\
\hline 1 & 0.03 & & \\
2 & 1.68 & & 0 \\
3 & 1.78 & $1 / 3 \times \mathrm{TS}$. & \\
4 & 1.93 & & \\
5 & 2.13 & & \\
6 & 2.89 & & \\
\hline
\end{tabular}




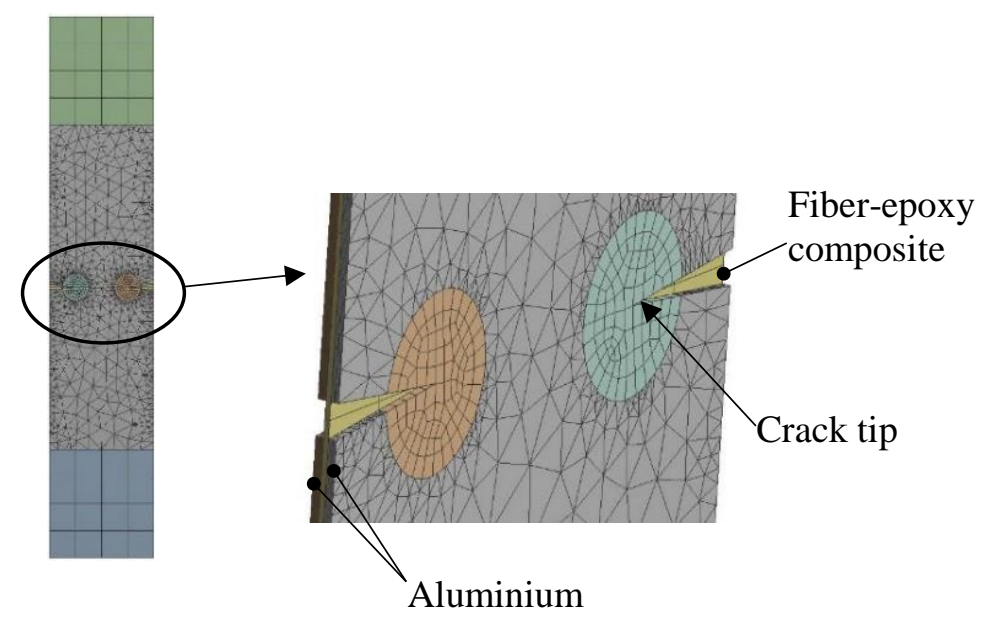

Figure 5. The meshed model used in the computer simulation.

\section{RESULTS}

The effect of the aluminium surface roughness at the interface to the tensile strength of the FMLs is shown in Figure 6. The figure shows that the surface roughness increases the tensile strength. When the value of $\mathrm{R}_{\mathrm{a}}$ is $0.33 \mu \mathrm{m}$, it represents the surface of the aluminium was not sandblasted, and its tensile strength is lowest in comparison to the higher value of the $R_{a}$, respectively, both in the cases of the fibre orientation $0^{\circ} / 90^{\circ}$ and $45^{\circ} / 45^{\circ}$. However, the significant influent of the surface roughness only takes place when the surface roughness is up to $1.93 \mu \mathrm{m}$. After that, the effect of the surface roughness increases slightly the tensile strength. In addition, the figure shows that the tensile strength with the fibre orientation $0^{\circ} / 90^{\circ}$ is higher than that of $-45^{\circ} /+45^{\circ}$ if the $R_{a}$ is lower than $1.93 \mu \mathrm{m}$. It is in contrast to the $\mathrm{R}_{\mathrm{a}}$ of $1.93 \mu \mathrm{m}$ or higher in which the tensile strength of the fibre orientation of $-45^{\circ} / 45^{\circ}$ is higher than that in the cases of $0 \% 190^{\circ}$. The variation of the tensile strength caused by the surface roughness has an association with the delamination at the interface between the aluminium and the fibre-epoxy composite laminate and the different deformation behaviour of the FMLs affected by the fibre orientation in the region adjacent to the fracture surface.

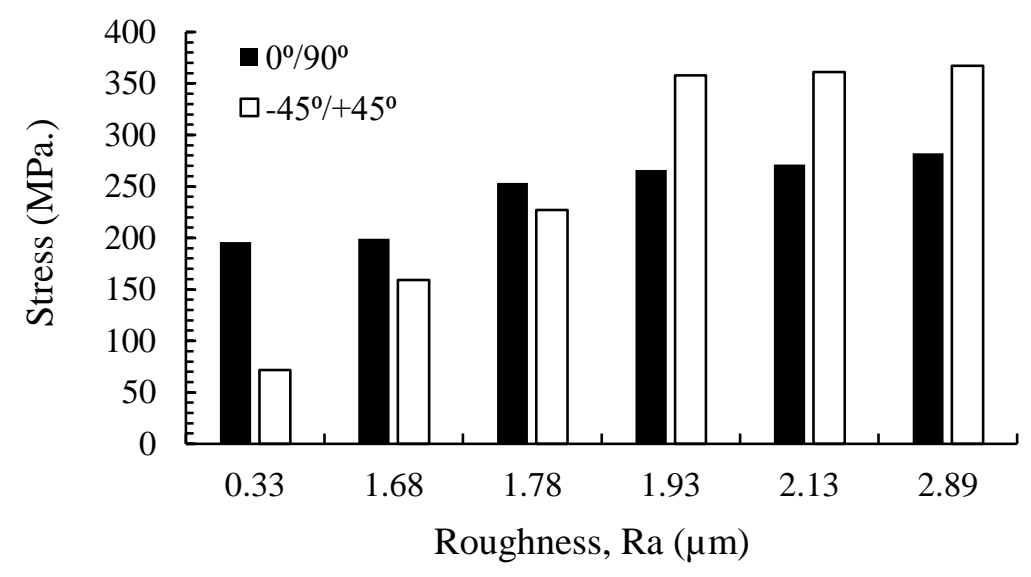

Figure 6 . The effect of roughness on tensile strength. 
Based on the results of the tensile test as shown in Figure 6, the fatigue crack propagation test was carried out under constant amplitude stress in which the maximum stress, $S_{\text {max., }}$ of the constant amplitude stress was applied one-third of the tensile strength, respectively, for every variation of $\mathrm{R}_{\mathrm{a}}$. Figure 7 shows an example of the FMLs after being cycled in the fatigue test with $\mathrm{R}_{\mathrm{a}}$ of $1.93 \mu \mathrm{m}$. The figure shows that the crack originated from the notches at both sides of the specimen. The black colour at the background as pointed by the white arrow is the carbon fibre-epoxy composite, and it is still intact although the aluminium laminate is fracture due to cyclic loads.

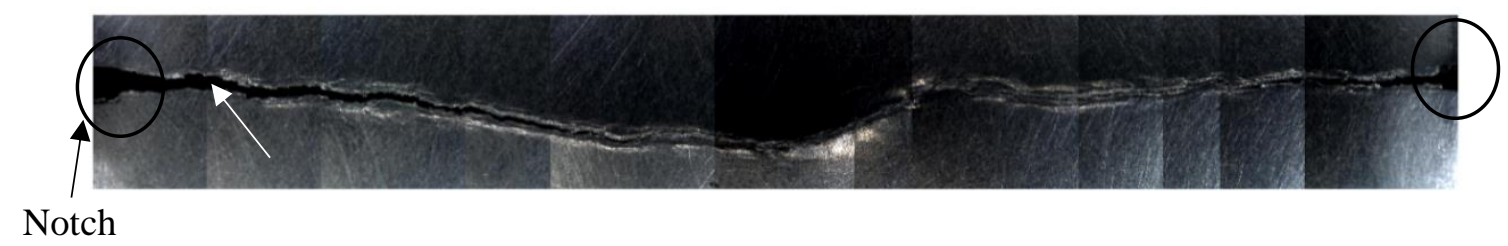

Figure 7. An example of fatigue crack propagation with the $R_{a}$ of $1.93 \mu \mathrm{m}$ and fibre orientation of $0^{\circ} / 90^{\circ}$.

The crack propagation behaviour affected by the various level of surface roughness on the FMLs is shown in Figure 8 for the fibre orientation of $0^{\circ} / 90^{\circ}$ and $45^{\circ} / 45^{\circ}$, respectively. In the case of FMLs with the fibre orientation of $0^{\circ} / 90^{\circ}$ as plotted in Figure 8(a), the fatigue life stated by the number of cycles, N, is increased by the value of $\mathrm{R}_{\mathrm{a}}$. However, after the $\mathrm{R}_{\mathrm{a}}$ is higher than $1.78 \mu \mathrm{m}$ the fatigue life decreases. In contrast to the previous cases, when the fibre orientation of the FMLs is $-45^{\%}+45^{\circ}$, the surface roughness decreases the fatigue life. In Figure 8(b) shows that the aluminium surface at the interface of the FMLs without sandblasting at which the value of $R_{a}$ is $0.33 \mu \mathrm{m}$ has the longest fatigue life, and the fatigue life decreases as the values of $R_{a}$ increases.

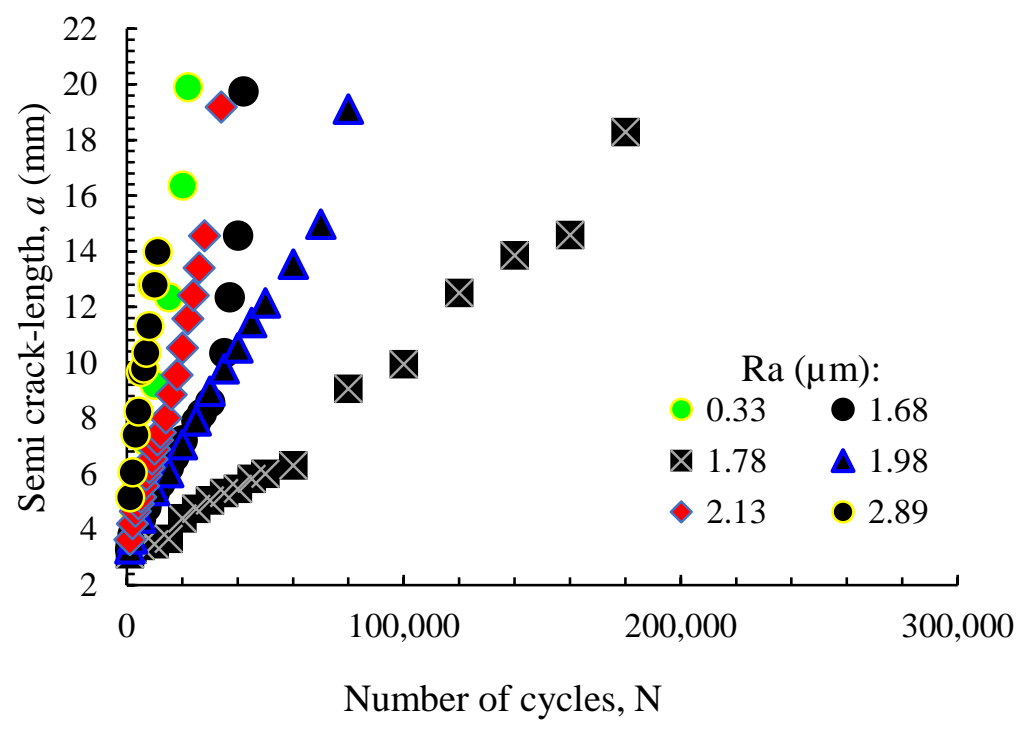

(a) fibre orientation of $0^{\circ} / 90^{\circ}$ 


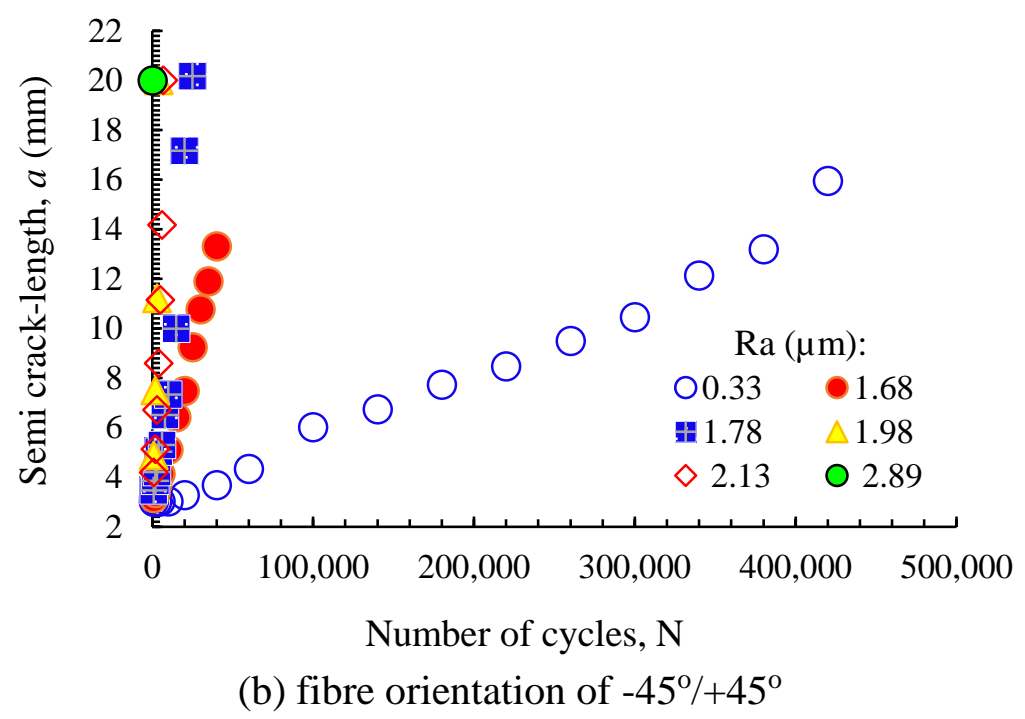

Figure 8 . The relation of number of cycles, N, to semi crack length, a, at different fibre orientation.

Figure 9 shows the relation of the semi crack length, $a$, to the crack propagation rate, da/dN, for the FMLs with fibre orientation $0 \% / 90^{\circ}$ and $-45^{\circ} / 45^{\circ}$, respectively. The figure shows that the crack propagation rate is influenced by the value of the surface roughness on both cases of the fibre orientation. When the $R_{a}$ is $1.78 \mu \mathrm{m}$, the crack propagation rate is lowest in comparison to other cases of the fibre orientation of $0 \% 90^{\circ}$ as shown in Figure 9(a). Because of this, the fatigue life is the longest. The phenomenon was also observed when the fibre orientation was $-45^{\%} / 45^{\circ}$ as shown in Figure 9 (b). However, the lowest crack propagation rate and the longest fatigue life occur on FMLs with the roughness of the aluminium surface to be $0.33 \mu \mathrm{m}$, and as the increase of the $\mathrm{R}_{\mathrm{a}}$ 's values, the crack propagation accelerates leading to the fatigue life to be lower.

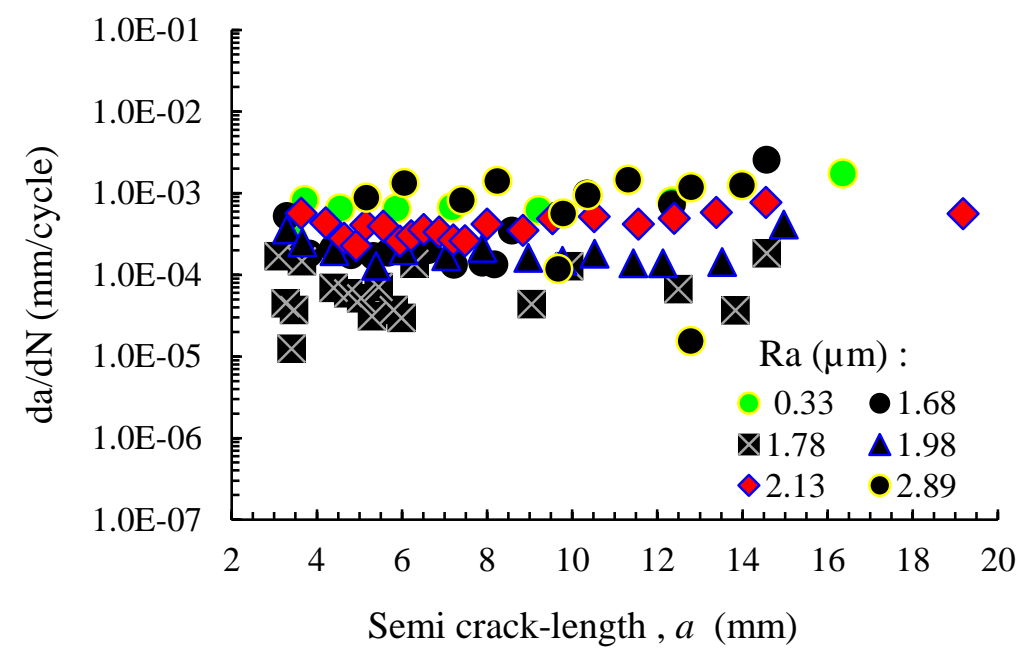

(a) Fibre orientation of $0^{\circ} / 90^{\circ}$ 


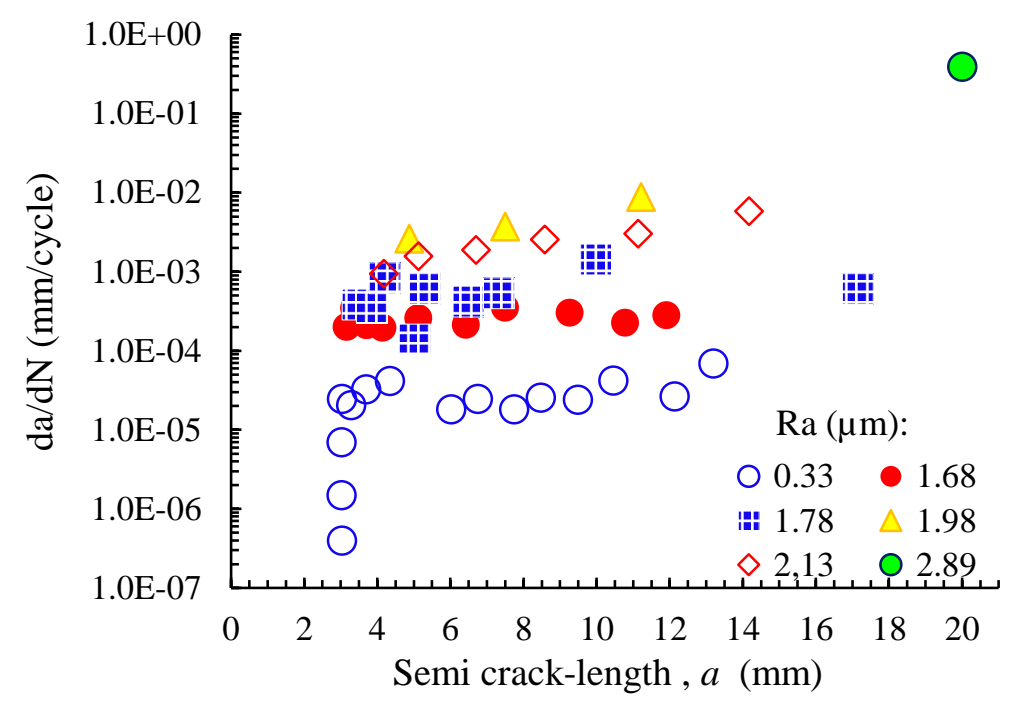

(b) Fibre orientation of $-45^{\%}+45^{\circ}$

Figure 9. The relation of semi crack length, a, to crack propagation rate, da/dN.

Due to the crack propagation behaviour in the aluminium laminate affects the fatigue life of the FMLs. Hence, the effect of the surface roughness to the fatigue life is summarised for every fibre orientation in Figure 10. It can be known that the increased surface roughness to be as high as $1.78 \mu \mathrm{m}$, the number of cycles required for failure taking place on the aluminium laminate can be increased when the fibre orientation is $0^{\circ} / 90^{\circ}$. However, when the value of surface roughness is higher than that value, the fatigue life becomes to be lower. The fatigue life of the FMLs with the fibre orientation of $45^{\circ} / 45^{\circ}$ has the highest fatigue life when the surface roughness of the aluminium is 0.33 $\mu \mathrm{m}$ and the increasing value of the surface roughness lowers drastically the fatigue life. Even, except in the case of $0.33 \mu \mathrm{m}$, the fatigue life of the fibre orientation of $0 \% / 90^{\circ}$ is higher than that of $-45^{\%}+45^{\circ}$.

The effect of the aluminium surface roughness at the interface of the FMLs may affect the adhesive bonding at the interface between the aluminium and the epoxy-fibre composite laminate, and the adhesive bonding may determine whether the delamination vulnerable to occur or not. This delamination associated with the tensile strength and fatigue crack propagation behaviour [10] in which the delamination over the crack region taking place behind the crack tip reduces the bridging stress $[2,7,9]$. In addition, the surface roughness may affect the stress distribution immediately in front of the crack tip of the aluminium laminate. The relation of aluminium surface roughness at the interface on tensile strength and the crack propagation behaviour of the FMLs are discussed in the next section. 


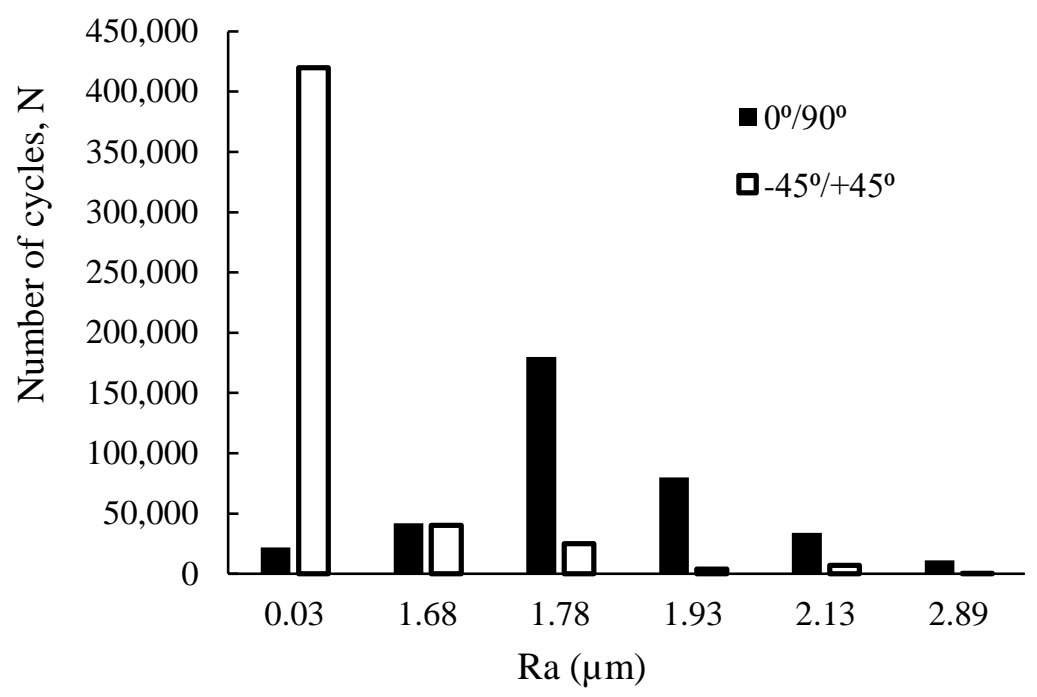

Figure 10. The effect of surface roughness, $\mathrm{R}_{\mathrm{a}}$, to the number of cycles, $N$.

\section{DISCUSSION}

Figure 11 shows the example of fracture images after being loaded in the tensile test when the aluminium surface roughness is $1.93 \mu \mathrm{m}$. Figure 11(a) is the fracture condition of FMLs with the fibre orientation of $0^{\circ} / 90^{\circ}$, and Figure $11(\mathrm{~b})$ is for the fibre orientation is $-45^{\circ} / 45^{\circ}$. In the former case, shows that the fracture surface is perpendicular to the load direction. However, in the letter case, the fracture surface is inclined to $45^{\circ}$, and the deformation at the region nearby the fracture surface is larger than the former case at which the deformation is not almost observable. In addition, in the letter case as pointed by the white arrow showing marks on the surface of the aluminium laminate indicates that there was local displacement being parallel to the fibre direction of $-45^{0} \%+45^{0}$. This is the reason why the delamination is occurring on the FMLs with the fibre direction of $45^{\circ} \%+45^{0}$ at the region nearby the fracture surface is larger than that of $0^{\circ} / 90^{\circ}$.

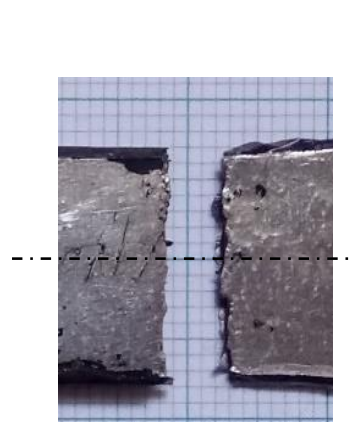

(a)

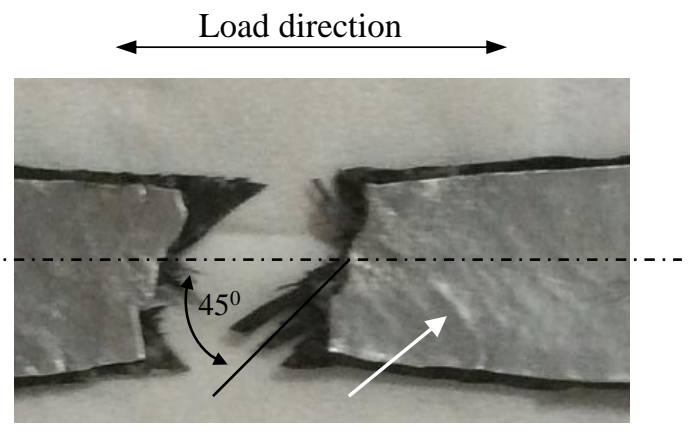

(b)

Figure 11. Fracture zone: (a) $0^{\circ} / 90^{\circ}$ and $1.93 \mu \mathrm{m}$; (b) $-45^{\circ} /+45^{\circ}$ and $1.93 \mu \mathrm{m}$.

The indication of the delamination occurring at the region near the fracture surface when the tensile test was carried out shown by the images in Figure 12. The images are examples of the aluminium surfaces, which were interfaced to the epoxy-carbon fibre composite. The black colour and encircled by the yellow line are the delamination area. 
These images show that in the case of the fibre orientation is $0^{\circ} / 90^{\circ}$, the delamination area, $A$, is smaller than that of $-45^{\circ} / 45^{\circ}$, and the rougher surface decreases the delamination area in both cases of the fibre orientation. The effect of the fibre orientation and the surface roughness to the delamination area in the present study is summarised in Figure 13

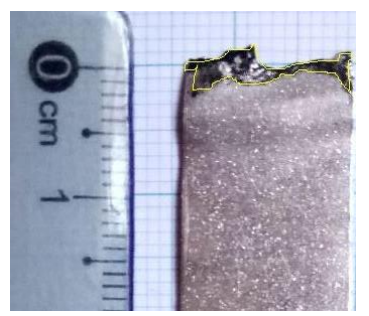

(a) $\mathrm{R}_{\mathrm{a}} 1.68 \mu \mathrm{m}, 0^{\circ} / 90^{\circ}$

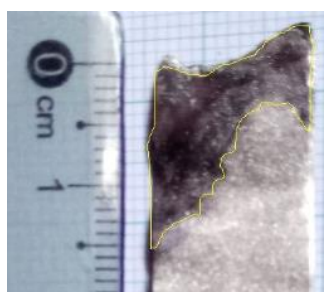

(d) $\mathrm{R}_{\mathrm{a}} 1.68 \mu \mathrm{m},-45^{\circ} / 45^{\circ}$

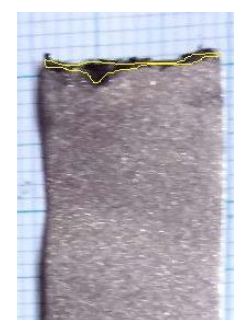

(b) $\mathrm{R}_{\mathrm{a}} 1.93 \mu \mathrm{m}, 0^{\circ} / 90^{\circ}$

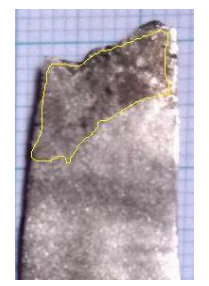

(e) $\mathrm{R}_{\mathrm{a}} 1.93 \mu \mathrm{m},-45^{\circ} /+45^{\circ}$

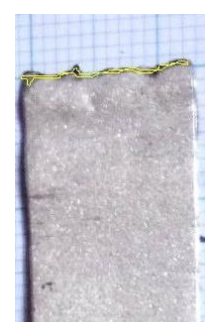

(c) $\mathrm{R}_{\mathrm{a}} 2.89 \mu \mathrm{m}, 0^{\circ} / 90^{\circ}$

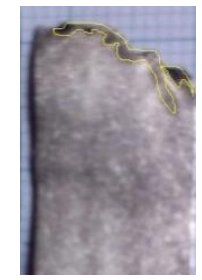

(f) $\mathrm{R}_{\mathrm{a}} 2.89 \mu \mathrm{m},-45^{\circ} / 45^{\circ}$

Figure 12. Examples of delamination.

Because the increasing surface roughness decreases the delamination area as plotted in Figure 13, thus the tensile strength of the FMLs increases also. However, although the delamination area of the $-45^{\circ} / 45^{\circ}$ cases is larger in comparison to another case, it is not mean that the tensile strength of the $-45^{\circ} / 45^{\circ}$ cases is always lower than that of $0^{\circ} / 90^{\circ}$. Especially, when the surface roughness is higher than $1.78 \mu \mathrm{m}$, the tensile strength of the $-45^{\circ} \% 45^{\circ}$ cases is higher than the of $0^{\circ} / 90^{\circ}$ cases. Besides the surface roughness, the orientation of the fibre also influences the tensile strength of the FMLs. In addition, the tensile strength is affected by the shear strength at the interface between the epoxy-carbon fibre composite and the aluminium laminate as shown in Figure 14. The figure shows that the aluminium surface without sandblasting having the surface roughness value as low as $0.33 \mu \mathrm{m}$ has almost the same shear strength on both fibre orientations. The shear strength increases gradually as the surface roughness increases, and the shear strength of FMLs with the fibre orientation of $-45^{\circ} / 45^{\circ}$ becomes higher than in the case of $0^{\circ} / 90^{\circ}$ when the surface roughness is $1.78 \mu \mathrm{m}$ or higher. Because of that, the tensile strength of the fibre orientation of $-45^{\circ} /+45^{\circ}$ is higher than that of $0^{\circ} / 90^{\circ}$ if the surface roughness is higher than $1.78 \mu \mathrm{m}$. 


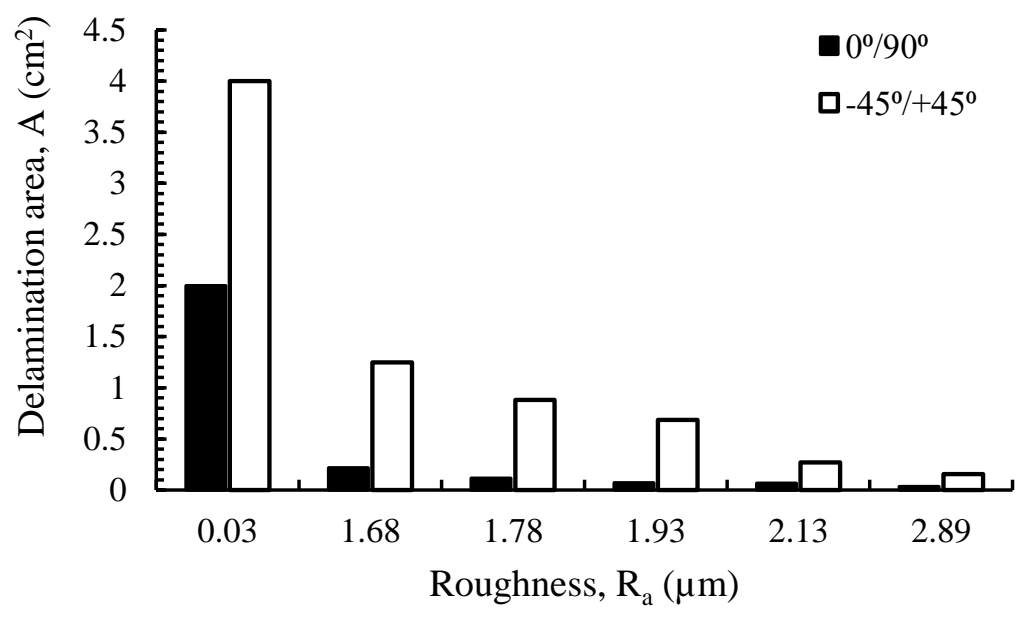

Figure 13. Delamination area due to static load.

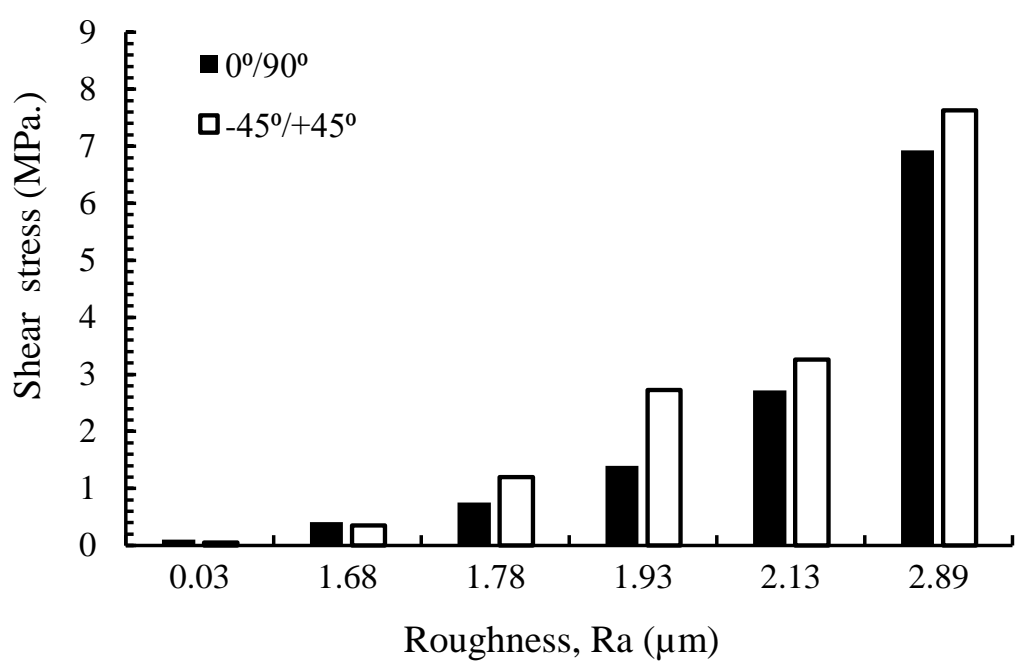

Figure 14. The shear stress of at the interface between the epoxy-carbon fibre composite and the aluminium laminates.

The fatigue-crack propagation behaviour of FMLs depends on the bridging stress over the crack region behind the crack tip. If the delamination occurs in the region over the crack, the bridging stress will decrease. It causes the stress intensity factor of the crack, which responsible for advancing the crack reduction. Consequently, the crack propagation rate accelerates $[2,7,16,17]$. Since delamination has an important role to the crack propagation and relates to the surface roughness, thus, the delamination area associated with the surface roughness is plotted in Figure 15 in which the cyclic loads caused that delamination area. It is in contrast to the delamination area caused by the static load as shown in Figure 13 in which the increase of the surface roughness reduces the delamination area, in the case of delamination area caused by the cyclic loads, the increase of the surface roughness leads to the area to become wider. The effect of the fibre orientation to the delamination caused by the cyclic loads has the same effect to the case of a static load, that is, the delamination in the case of the fibre orientation of $45^{\circ} / 45^{\circ}$ is wider than that of $0^{\circ} / 90^{\circ}$. Therefore, the fatigue life of the FMLs with the fibre orientation 
of $-45^{\circ} / 45^{\circ}$ is shorter in comparison to that occurring at the FMLs with the fibre orientation of $0^{\circ} / 90^{\circ}$ in the exception when the value of $\mathrm{R}_{\mathrm{a}}$ is $0.33 \mu \mathrm{m}$. In addition, the increasing delamination area affected by the cyclic loads at the FMLs with the fibre orientation of $-45^{\circ} / 45^{\circ}$ as the increasing of the value of $R_{a}$ leads to shortening the fatigue life. However, in the case of fibre orientation of $0^{\circ} / 90^{\circ}$, the effect of cyclic loads to the delamination is less pronounced in comparison to another case, and the delamination area is almost stagnant when the values of $\mathrm{R}_{\mathrm{a}}$ are from 1.68 to $2.13 \mu \mathrm{m}$. This causes their fatigue life is longer than what take places in the case of fibre orientation of $-45^{\circ} / 45^{\circ}$. Besides that, when the value of $R_{a}$ is $1.78 \mu \mathrm{m}$, the fatigue life of FMLs with the fibre orientation of $0^{\circ} / 90^{\circ}$ is longest than other various surface roughness although the delamination area is stagnant. It is an indication that the fatigue life is not only affected by the delamination but also other factors.

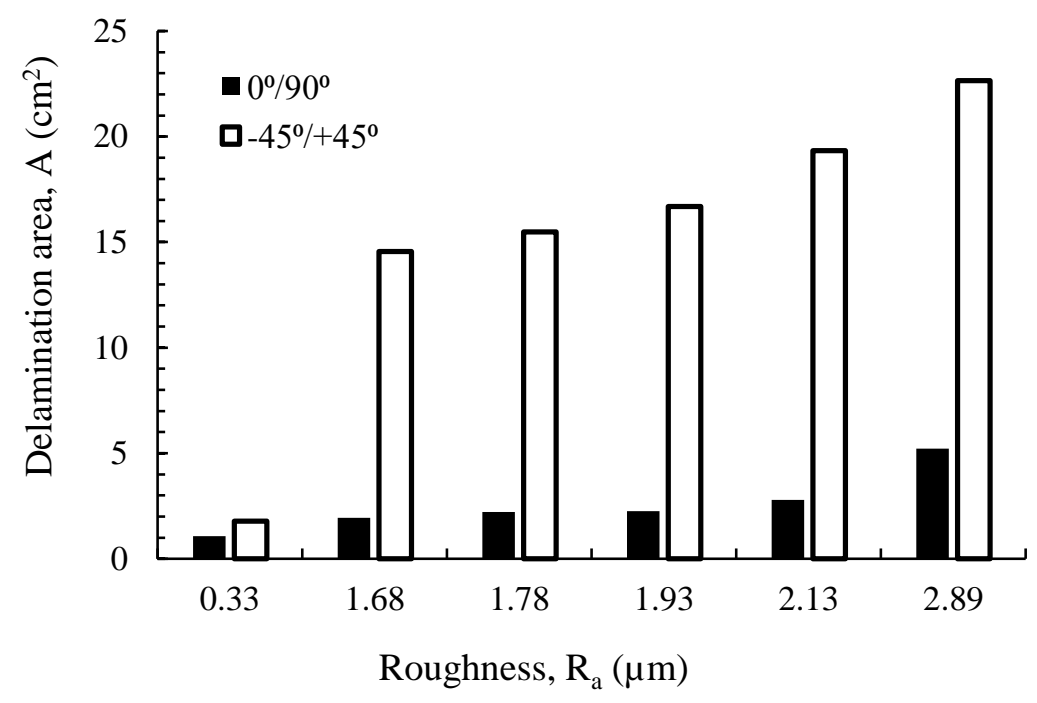

Figure 15. The delamination area due to cyclic loads.

Figure 16 shows an example of the contour of stress distribution in the region near the crack tip on the aluminium laminate. The figure shows that the stress concentrates just in front of the crack tip as indicated by the red colour, and as the concentration reduces, the colour gradually shifts to the light green colour indicating that the crack tip effect is not pronounced anymore. The example of the contour of stress distribution in the figure is the FMLs with the fibre orientation of $-45^{\circ} /+45^{\circ}$ and the $R_{a}$ of $1.93 \mu \mathrm{m}$, and when it

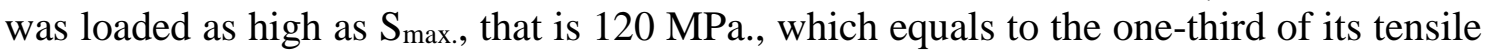
strength. The stress concentration just in front of the crack tip for various cases of the surface roughness is summarised in Figure 17. From this figure, the stress concentration varies depending on the surface roughness and the fibre orientation. It is known that the stress concentration taking place just in front of the crack tip when the surface roughness is $0.33 \mu \mathrm{m}$ with the fibre orientation of $-45^{\circ} /+45^{\circ}$ has the lowest value, thus, in the present study, this has the longest fatigue life. The fatigue life in this fibre orientation decreases as the value of $R_{a}$ increases because the stress concentration tends to be higher as increasing the surface roughness. Concerning Figure 10 in the case of the FMLs with the fibre orientation of $0^{\circ} / 90^{\circ}$ shows that the fatigue life is longest when the value of $R_{a}$ is of $1.78 \mu \mathrm{m}$. This is due to the stress concentration being the lowest in this case. In addition, except for $\mathrm{R}_{\mathrm{a}}$ of 0.33 and $1.68 \mu \mathrm{m}$, the stress concentrations taking place in the case of 
fibre orientation of $0^{\circ} / 90^{\circ}$ are lower than that taking place in the case of $-45^{\circ} /+45^{\circ}$. Because of that, mostly the fatigue life of the FMLs with the fibre orientation of $0^{\circ} / 90^{\circ}$ is longer than that of the $-45^{\circ} / 45^{\circ}$.

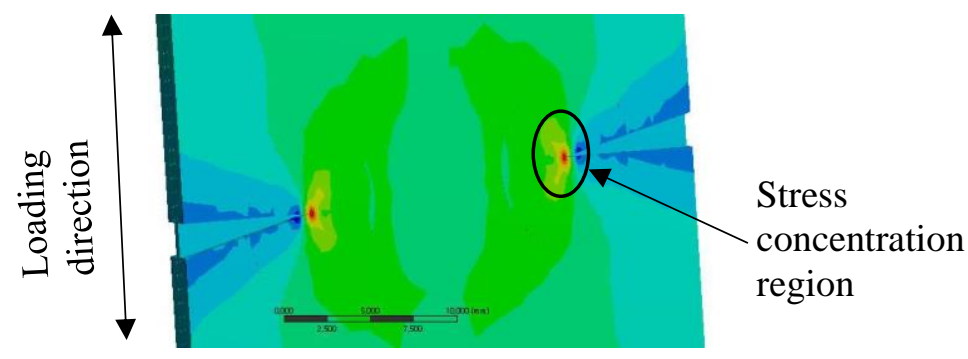

Figure.16 An example of the contour of stress distribution.

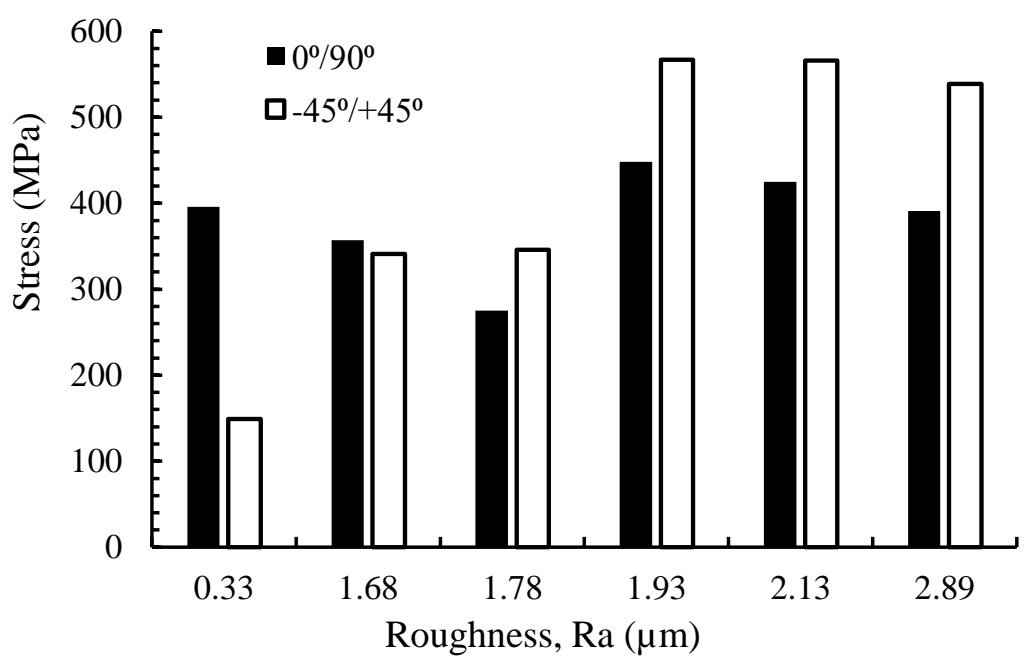

Figure 17. Stress just in front of the crack tip on the aluminium laminate.

The fatigue crack is well known to be more vulnerable to initiate from the surface, which is rougher than the smooth surface [5]. Figure 18 shows examples of the image of the morphology of the aluminium surfaces after being sandblasted, and the surface roughness is 1.68 and $1.93 \mu \mathrm{m}$, respectively, in Figure 18(a) and Figure 18(b). The figure provides images showing that the random ridge and groove are denser on the higher surface roughness. Because the aluminium surface at the interface side is rougher than that on the observation side on which the observation of the crack propagation was carried out, the crack initiation at which crack begins to propagate is not the same on the FMLs with and without sandblasted as shown in Figure 19. In Figure 19(a) shows that in the case of $R_{a}$ is $0.33 \mu \mathrm{m}$ at which the aluminium surface at the interface between the aluminium and the fibre-epoxy was not sandblasted, the striation as pointed by the blue arrow on the fracture surface is perpendicular to the crack propagation observed from the observation side. This indicates that the crack propagation initiated from the notch. The pattern of striation on the fracture surface is not the same as in the previous case as shown in Figure 19(b), in this case, the striation emerged from the interface side, which had been sandblasted; thus the striation is not perpendicular to the observed crack propagation. 
Therefore, it is plausible that the cracks from a rougher surface are easier to propagate, and as a result, the fatigue life is prone to be shorter if the aluminium surface is rougher.

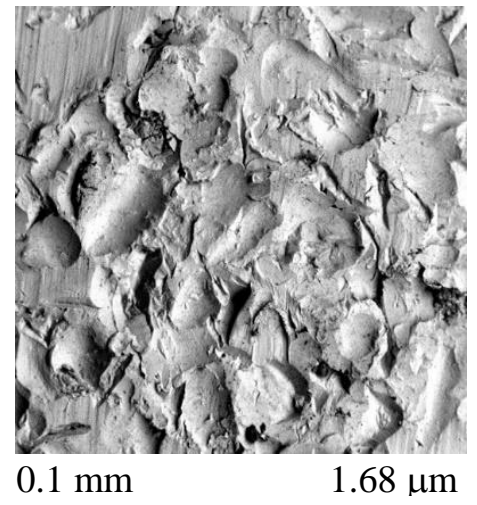

(a)

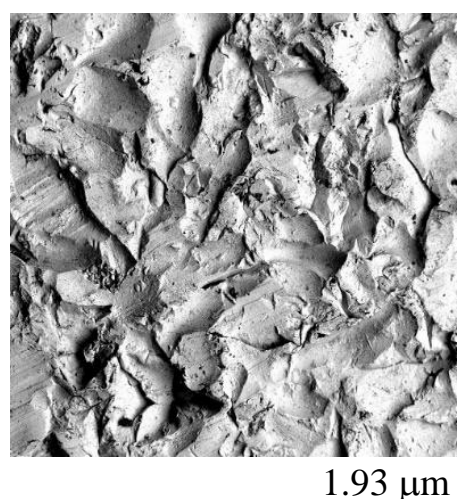

(b)

Figure 18. Morphology of the sandblasted aluminium-surfaces.

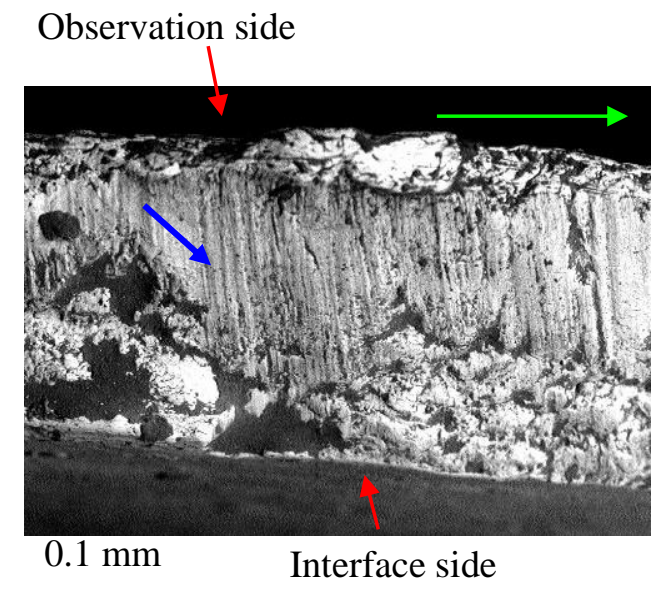

(a) $\mathrm{R}_{\mathrm{a}}=0.33 \mu \mathrm{m}$

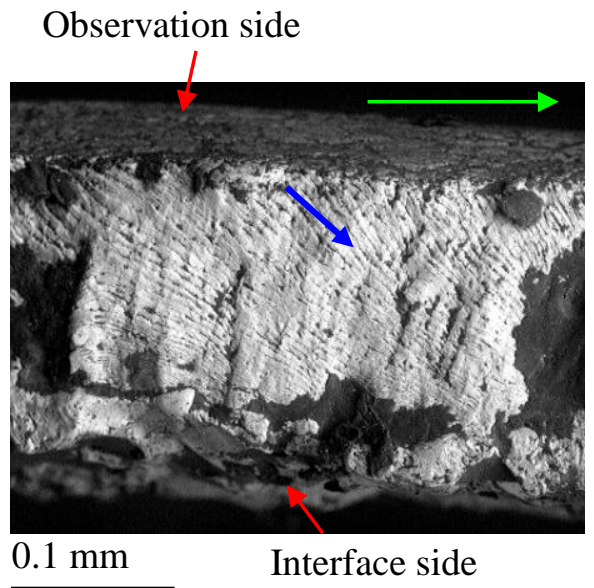

(b). $\mathrm{R}_{\mathrm{a}}=1.93 \mu \mathrm{m}$

Figure 19. The pattern of striation on fatigue fracture surface at different surface roughness.

The present study shows that the increased surface roughness in the interface side of the FMLs can increase its strength relating to the static load, and it depends on the fibre orientation. However, when the FMLs carries the cyclic loads, the surface condition at the interface side may determine the lifetime associating with the crack propagation. The rougher surface may endanger a lifetime of a component. Besides the surface condition, the cyclic load's condition in connection with the stress condition in front of the crack tip of the metal laminate during the crack propagates also influence the lifetime. Moreover, depending on the fibre orientation, it was found that in a certain condition of the surface roughness together with the condition of the cyclic load may enhance the lifetime. Unfortunately, in the present study, how the mechanism between them enhance the lifetime associating with the crack propagation have not been completely resolved yet. Thus, it may be conducted very shortly for a deeper investigation. 


\section{CONCLUSION}

The conclusions obtained from this study are as follows:

i. The study shows that the crack propagation behaviour on the FMLs is affected by factors such as the surface roughness of the aluminium at the interface of the FMLs fibre orientation and the stress concentration just in front of the crack tip.

ii. In the cyclic loads in which the maximum cyclic loads is one-third of their tensile strength the delamination development together with the stress concentration just in front of the crack tip dominate to affect the fatigue life. When the delamination area and stress concentration are lower, the fatigue life is higher as indicated in the case of fibre orientation $-45^{\circ}+45^{\circ}$ with $0.33 \mu \mathrm{m}$ of surface roughness. The fatigue life is lower when the surface roughness increases because of higher stress concentration and area of delamination. In the case of fibre orientation of $0^{\circ} / 90^{\circ}$, the lowest stress concentration occurs when the surface roughness is $1.78 \mu \mathrm{m}$ and the delamination area is relatively low. Hence, the fatigue life is the longest.

iii. The tensile strength of the FMLs is affected by the aluminium surface roughness at the interface between the aluminium and the fibre-epoxy composite. The rougher surface increases the shear strength of the interface. Because of it, the delamination is not easy to develop. Thus, the tensile strength of the FMLs is higher.

iv. The fatigue life of the FMLs based on the crack propagation is not determined by the statically tensile strength, but it depends on the development of the delamination of the interface on the crack wake and the stress concentration in front of the crack tip if the maximum of the cyclic load is one-third of their tensile strength.

v. The increasing value of the surface roughness has to be considered a potential factor in reducing the lifetime because the crack can initiate easily from the rougher surface.

\section{REFERENCES}

[1] Callister WDJ, Retwisch DG. Introduction in fundamentals of materials science and engineering, an integrated approach. 3th ed. New Jersey: John Wiley \& Sons; 2008.

[2] Alderliesten R. Fatigue crack propagation and delamination growth in glare. 1st ed. Delft: DUP Science; 2005.

[3] Jones RM. Introduction to composite materials-mechanics of composites materials. 2th ed. Philadelphia: Taylor \& Francis; 1999.

[4] Stephens RI, Fatemi A, Stephens RR, Fuchs HO. Metal fatigue in engineering. 1st ed. New York: John Wiley \& Sons; 2001.

[5] Barsom JM, Rofle ST, Stress analysis for members with crack, in fracture and fatigue control in structure. 3rd ed. Philadelphia: ASTM; 1999.

[6] Anindito P, Makabe C. The crack growth behavior after overloading on rotating bending fatigue. Engineering Failure Analysis 2009; 16(7): 2245-2254.

[7] Wilson GS, Alderliesten RC, Benedictus R. A generalized solution to the crack bridging problem of fiber metal laminates. Engineering Fracture Mechanics 2013; 105(9): 65-85. 
[8] Huang Y, Liu J, Huang X, Zhang J, Yue G. Delamination and fatigue crack growth behavior in fiber metal laminates (glare) under single overloads. International Journal of Fatigue 2015; 78(9): 53-60.

[9] Dadej K, Bienias J. Residual fatigue life of carbon fibre aluminium laminates. International Journal of Fatigue 2017; 100(1): 94-104.

[10] Jones R, Kinloch AJ, Hu W, Surowska B. Cyclic-fatigue crack growth in composite and adhesively-bonded structures: the FAA slow crack growth approach to certification and the problem of similitude. International Journal of Fatigue 2016; 88(10): 10-18.

[11] Nojavan S, Schesser D, Yang QD. A two-dimensional in situ fatigue cohesive zone model for crack propagation in composites under cyclic loading. International Journal of Fatigue 2016; 82(3): 449-461.

[12] D'Amore A, Giorgio M, Grassia L. Modeling the residual strength of carbon fiber reinforced composites subjected to cyclic loading. International Journal of Fatigue 2015; 78(9): 31-37.

[13] Liu Y, Zhang C. A critical plane-based model for mixed-mode delamination growth rate prediction under fatigue cyclic loadings. Composites Part B 2018; 139(8): 185-194.

[14] Spronk SWF, Sen I, Alderliesten RC. Predicting fatigue crack initiation in fibre metal laminates based on metal fatigue test data. International Journal of Fatigue 2015; 70(1): 428-439.

[15] Pan Y, Wu G, Huang Z, Li M, Ji S, Zhang Z. Effect of surface roughness on interlaminar peel and shear strength of CFRP/Mg laminates. International Journal of Adhesion and Adhesives 2017; 79(8): 1-7.

[16] Tiedemann D, Bär J, Gudladt HJ. The crack propagation rate according to notches and overload levels. In: 20th European Conference on Fracture (ECF20), Trondheim, Norway, pp. 1359-1364; 2014.

[17] Makabe C, Anindito P, McEvily AJ. Effects of surface deformation and crack closure on fatigue crack propagation after overloading and under loading. International Journal of Fatigue 2004; 26(12): 1341-1348. 